\title{
Characteristics, types and causes of chest pain in an urban family practice secondary care center in South India
}

\author{
YESHVANTH KUMAR G.S. ${ }^{1, A-F}$, PRINCE CHRISTOPHER RAJKUMAR HONEST ${ }^{1, A-F}$, \\ APOORVA SUBRAMANIAN ${ }^{2, A}$, B, E-G, RANJIT ABRAHAM ${ }^{2, A}, \mathrm{~B}, \mathrm{E}-\mathrm{G}$, SARAN TEJA VELAGA ${ }^{2, A, B, E-G}$, \\ RUBY ANGELINE PRICILLA ${ }^{3, A-G}$, KIRUBAH VASANDHI DAVID ${ }^{1, A-G}$, SUNIL ABRAHAM ${ }^{1, D, E}$ \\ ${ }^{1}$ Department of Family Medicine, Christian Medical College and Hospital, Vellore, India \\ ${ }^{2}$ Medical Undergraduate student, Christian Medical College and Hospital, Vellore, India \\ ${ }^{3}$ Department of Community Medicine, Christian Medical College and Hospital, Vellore, India
}

A - Study Design, B - Data Collection, C - Statistical Analysis, D - Data Interpretation, E - Manuscript Preparation, F - Literature Search, G - Funds Collection

Summary Background. Chest pain is a common diagnostic problem faced by primary and emergency care physicians. We are taught to consider the cardiac cause of chest pain as the usual cause from our undergraduate textbooks. Though the cardiac cause of chest pain is one of the more serious causes, it may not be the common one. There was a paucity of data available concerning this common problem in the Indian context. We present an observational study of causes of chest pain in 254 adults presenting to an ambulatory secondary care unit.

Material and methods. All consecutive adults (over 18 years of age) presenting with chest pain to the urban family health center were administered a questionnaire documenting location, severity, characteristic and cause of chest pain as diagnosed by relevant clinical examination and appropriate investigations. This was done in the time period from September 2014 to July 2016.

Results. A total of 254 adults with chest pain were studied, among whom $73.6 \%$ (187) were female. The most common diagnosis as to the cause of chest pain made by the treating physician was of a gastro-esophageal cause $(41.3 \%, 105)$. A cardiac origin of chest pain was diagnosed in $18.5 \%$ (47) of the patients.

Conclusions. The causes of chest pain in adults vary with the setting and the target population. It is mostly non-cardiac in ambulatory care practices in primary and secondary care units. However, we need to be clinically vigilant and apply a robust approach in diagnosing chest pain.

Key words: chest pain, family practice, secondary care, India.

Kumar GSY, Rajkumar Honest PC, Subramanian A, Abraham R, Velaga ST, Pricilla RA, David KV, Abraham S. Characteristics, types and causes of chest pain in an urban family practice secondary care center in South India. Fam Med Prim Care Rev 2017; 19(4): 377-381, doi: https://doi.org/10.5114/fmpcr.2017.70810.

\section{Background}

Chest pain is a common symptom in all health care settings and can be caused by a wide range of disease conditions. Some of these could be due to treatable causes, such as musculoskeletal disorders with favorable outcomes; others could be due to potentially fatal life-threatening conditions, such as acute coronary syndrome [1]. Most patients with chest pain are initially seen by a general practitioner (GP), who thus has the challenge of triaging the patients. In order to correctly triage patients, GPs need to know the common causes of chest pain and their frequency of occurrence in the population.

GPs generally follow a process of probabilistic reasoning by combing the initial likelihood for a given cause (pre-test probability) with the information gathered from the patient's history and clinical examination. This process guides the GP to reach a final differential diagnosis (post-test probability) [2].

A study of the symptoms of chest pain that looks at how patients present with it, what other underlying conditions there are and their respective frequencies and the final diagnoses made has not been done in the Indian health care setting. The knowledge derived from such a study would be of immense practical value for GPs in India by providing pre-test probability of a diagnosis for these symptoms.
Symptoms of chest pain can be broadly divided into cardiac chest pain (CCP) or non-cardiac chest pain (NCCP) based on the etiology. The concern of the emergency physician is in diagnosing and managing CCP in as short a time frame as possible. The GP is faced with the challenging task of differentiating the various causes of chest pain and make an appropriate referral. Though CCP is definitely more life threatening, there is significant morbidity in NCCP as well. The GP uses the history and clinical examination to differentiate the various causes of NCCP. CCP is usually left sided with radiation, aggravated by exertion, relieved by rest and is more likely in patients who have a past history of heart disease, hypertension or diabetes mellitus. When a patient has a cough, rapid respiratory rate or chest pain that worsens on deep inspiration, the most likely cause of chest pain is a pulmonary cause. The clinical characteristics of NCCP of musculoskeletal origin are localized pain that is reproducible by palpation and aggravated by movement. The features that are suggestive of NCCP due to gastroenterological causes are retrosternal pain accompanied by esophageal symptoms, such as dyspepsia, nausea, heartburn and regurgitation [3]. Other causes of NCCP documented in primary care are panic disorder, anxiety and skin conditions, such as herpes zoster.

The prevalence of these various causes differs in countries where the epidemiology of NCCP has been studied in primary care settings. In Belgium, for example, a cardiac diagnosis was 
made in $13 \%$ of patients with chest pain in primary care. Among NCCP, a musculoskeletal cause was attributed in $21 \%$, while $20 \%$ was due to a pulmonary cause [4]. In the U.K. and Switzerland, the proportion of consultations for chest pain in primary care varied from $1-2.7 \%$ [5-7]. The prevalence of NCCP due to a musculoskeletal cause was $21-51 \%$, gastroenterological causes were $8-19 \%$, and a psychogenic cause was 8-17\% [5-7].

There is a paucity of studies on the prevalence of various causes of chest pain in the Indian general practice setting. In India, a medical graduate who has successfully completed the undergraduate Bachelor of Medicine and Bachelor of Surgery course (MBBS) and has been registered with the Indian Medical Council is eligible to practice as a GP. There are only a few graduates who complete specialist training in Family Medicine. During undergraduate training, being predominantly in tertiary care institutes, one is taught to consider a cardiac cause as the most probable cause for patients presenting with chest pain. Studies have shown this may not be applicable in primary care settings. To the best of our knowledge, there are no current statistics available in the rural or urban primary or secondary care settings on common causes of chest pain and its associated characteristics and frequencies. We, therefore, perceived a need to conduct such a study.

\section{Objectives}

We planned an observational cross-sectional study with the following objectives:

- To identify the common causes of chest pain in a family practice secondary care unit located in an urban area/ /serving an economically disadvantaged urban population.

- To describe the characteristics of patients who present with chest pain.

- To assess the association, if any, of the described characteristic with the causes of chest pain.

\section{Material and methods}

\section{Study design}

The study design was an observational cross-sectional study.

\section{Study setting}

The study setting was the urban health care unit of a medical college and hospital. The unit is located two kilometers away from the tertiary care main hospital and manned by family medicine specialists, community health specialists, medical officers and post-graduate residents. It is a secondary level unit and caters to a population of approximately 200,000 . The population consists mostly of economically disadvantaged urban slum residents. The average number of ambulatory care visits per year is approximately 70,000 . The unit has a 46 -bed inpatient ward and a 2-bed labor ward. As the unit specializes in family medicine, the physicians see patients of all ages. The common diseases seen are acute respiratory illnesses, acute febrile episodes, gastroenteritis, mental health disorders and chronic morbidities, such as diabetes mellitus, hypertension, ischemic heart diseases, seizure disorders, chronic obstructive pulmonary disease and musculoskeletal disorders. There are daily outreach clinics that cater to the neighboring urban residents, wherein a similar profile of morbidities is seen.

\section{Study participants}

The study participants were recruited between September 2014 and July 2016 using a questionnaire that included type, duration, severity and characteristics of chest pain. The questionnaire was filled in by the treating physician. After obtaining informed consent in their local language, all consecutive adults (over 18 years of age) presenting with chest pain to the urban health care unit were administered a questionnaire by the treating physician, wherein clinical characteristics of the pain and any underlying co-morbidity were inquired. A focused physical examination was done and relevant investigations ordered based on the differential diagnosis and on the algorithm (Figure 1). The algorithm was developed after a discussion with all the treating physicians of the unit. They also ensured that all the study participants were given the best available standard of care for their illness. The final diagnosis was made by the treating physician based on the collective clinical and investigative findings.

\section{Variables}

We documented the demographic details of the participants: the baseline characteristics, the examination findings and the investigations carried out. We recorded the characteristics of chest pain and tabulated the various factors associated with cardiac and non-cardiac chest pain.

\section{Data sources/measurement}

The data was recorded in written format in the questionnaire by the treating physicians. The severity of chest pain was documented using the Wong-Baker FACES ${ }^{\circledR}$ pain rating scale [8].

\section{Statistical methods}

The data was entered using Microsoft Access 2000 and statistics tabulated using SPSS Statistics for Windows, Version 17.0. (Chicago, U.S.A.). The chi-squared test of association or Fisher's exact probability tests were used to assess the association between the cardiac and non-cardiac cause of chest pain with associated variables such as age, sex, gender, past history of hypertension, diabetes or ischemic heart disease. An unadjusted binary logistic regression analysis was done using the step-wise method.

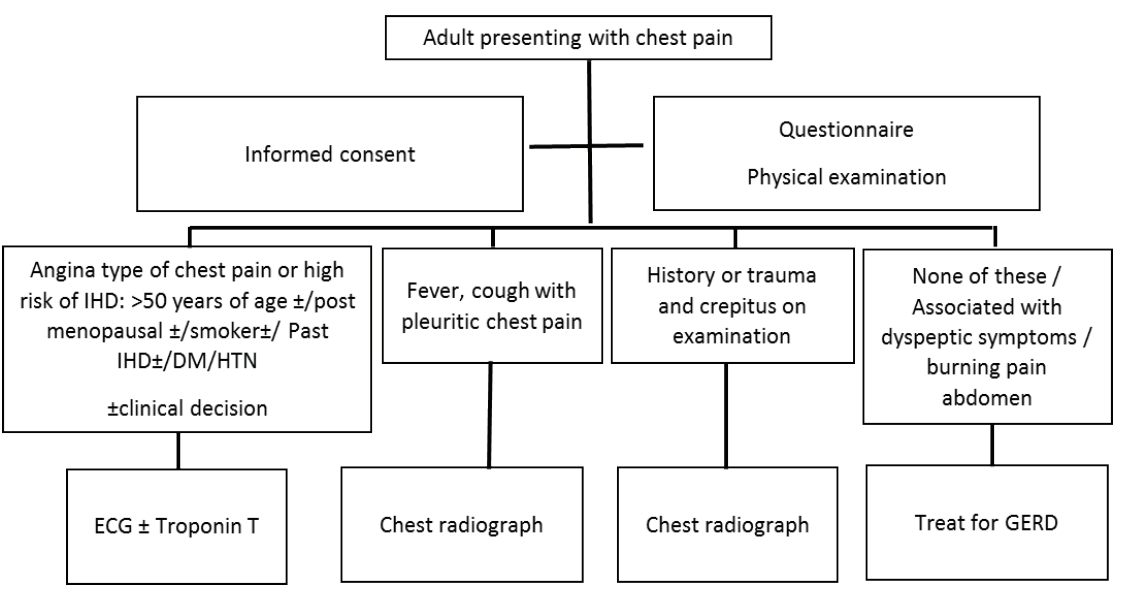

Figure 1. Detailed diagrammatic algorithm of the study 


\section{Ethical approval}

The Institutional Review Board and Ethics Committee (IRB) of the Institution approved the conduct of the study (vide IRB minutes of the meeting (8696) held on 26 February 2014; approval dated 7 April 2014).

\section{Results}

\section{Participants}

The characteristics of chest pain were recorded in 254 patients. The percentage of females was $73.6 \%$, as reflected from our outpatient visit timings, which are in the morning, preventing access to working male members (Table 1 ).

\begin{tabular}{|c|c|c|c|}
\hline $\begin{array}{l}\text { Variable } \\
(n=254) \\
\end{array}$ & Number (\%) & $\begin{array}{l}\text { Variable } \\
(n=254) \\
\end{array}$ & Number (\%) \\
\hline \multicolumn{2}{|l|}{ Age in years } & \multicolumn{2}{|l|}{ Family history } \\
\hline$\leq 20$ & $3(1.2)$ & $\begin{array}{l}\text { diabetes } \\
\text { mellitus }\end{array}$ & $51(20.1)$ \\
\hline $21-40$ & $90(35.4)$ & hypertension & $44(17.3)$ \\
\hline $41-60$ & $126(49.6)$ & $\begin{array}{l}\text { cardiac prob- } \\
\text { lems }\end{array}$ & $13(5.1)$ \\
\hline$>60$ & $35(13.8)$ & $\begin{array}{l}\text { respiratory } \\
\text { problems }\end{array}$ & $4(1.6)$ \\
\hline \multicolumn{2}{|l|}{ Gender } & \multicolumn{2}{|l|}{ Examination } \\
\hline Male & $67(26.6)$ & pallor & $22(8.7)$ \\
\hline Female & $187(73.6)$ & pedal edema & $2(0.8)$ \\
\hline \multicolumn{2}{|l|}{ Personal history } & $\begin{array}{l}\text { normal heart } \\
\text { sounds }\end{array}$ & $250(97.2)$ \\
\hline Smoking & $39(15.4)$ & $\begin{array}{l}\text { normal breath } \\
\text { sounds }\end{array}$ & $248(95.6)$ \\
\hline $\begin{array}{l}\text { Alcohol con- } \\
\text { sumption }\end{array}$ & $23(9.1)$ & $\begin{array}{l}\text { chest wall } \\
\text { tenderness }\end{array}$ & $74(29.1)$ \\
\hline \multicolumn{2}{|c|}{ Past medical history } & \multicolumn{2}{|l|}{ Investigations } \\
\hline $\begin{array}{l}\text { Diabetes } \\
\text { mellitus }\end{array}$ & $67(26.4)$ & $\begin{array}{l}\text { electro cardio- } \\
\text { graph }\end{array}$ & $133(52.4)$ \\
\hline Hypertension & $83(32.7)$ & chest X-ray & $43(16.9)$ \\
\hline Tuberculosis & $17(6.7)$ & $\begin{array}{l}\text { cardiac } \\
\text { enzymes }\end{array}$ & $31(12.2)$ \\
\hline $\begin{array}{l}\text { Respiratory } \\
\text { conditions }\end{array}$ & $16(6.3)$ & & \\
\hline $\begin{array}{l}\text { Cardiac condi- } \\
\text { tions }\end{array}$ & $14(5.5)$ & & \\
\hline
\end{tabular}

\section{Descriptive data}

Nearly half of the patients $(126 / 254,49.6 \%)$ were from the age group of 41 to 60 years. The proportion of patients consuming alcohol $(23 / 254,9.1 \%)$ and smoking $(39 / 254,15.4 \%)$ was relatively low, as it was predominantly female patients. More than half had a significant medical history of diabetes $(67 / 254$, $26.4 \%$ ) and hypertension (83/254, 32.7\%) (Table 1).

\section{Main results}

The onset of chest pain was equally distributed between less than three days and a longer duration. The most common location of chest pain described was central by 134 patients (52.8\%). Nearly two-thirds of the patients experienced chest pain greater than 5 on the pain scale (Table 2). Some of the aggravating factors described by patients included exercise ( 66
(26\%)) and food (48 (18.9\%)). Patients had chest pain along with associated symptoms of dyspepsia (51 (20.1\%)), breathlessness (46 (18.1\%)) and nausea or vomiting (31 (12.2\%)). Common relieving factors for chest pain described were rest (85 (33.5\%)) and food $(25(9.8 \%))$, and many had unspecified relieving factors $(121(47.6 \%))$.

The most often ordered investigation was an ECG in 133 patients (52.4\%) (Table 1). Biomarkers for myocardial injury, serum Troponin T was ordered in 31 patients, among whom 8 had elevated Troponin T levels.

After eliciting a history, appropriate physical examination and investigations, the most common diagnosis as a cause of chest pain made by the physicians was gastro-esophageal reflux disease (GERD) (105 (41.3\%)). The next common cause was musculoskeletal $(65(25.6 \%))$. A cardiac cause of chest pain was diagnosed in 47 patients (18.5\%). In patients more than 70 years of age, the cause of chest pain was attributed more to cardiovascular cause, whereas in those younger than 20 years, the cause was attributed more as a musculoskeletal cause (Figure 2). Male patients and those older than 40 years of age showed a significantly higher proportion of cardiac causes of chest pain $(p<0.015$ and $p<0.001$ ) (Table 3). Moreover, patients with a positive history of diabetes and hypertension were more significantly diagnosed to have a cardiac cause of chest pain $(p<0.0001)$.

\begin{tabular}{|c|c|c|c|}
\hline $\begin{array}{l}\text { Characteris- } \\
\text { tics }\end{array}$ & Number (\%) & $\begin{array}{l}\text { Characteris- } \\
\text { tics }\end{array}$ & Number (\%) \\
\hline $\begin{array}{l}\text { Onset } \\
(n=253)\end{array}$ & & $\begin{array}{l}\text { Progression } \\
(n=254)\end{array}$ & \\
\hline$<3$ days & $92(36.4)$ & constant & 124 (48.8) \\
\hline $\begin{array}{l}3 \text { days to } 2 \\
\text { weeks }\end{array}$ & $80(31.6)$ & worsened & 104 (40.9) \\
\hline$>2$ weeks & $81(32.0)$ & decreased & $26(10.2)$ \\
\hline $\begin{array}{l}\text { Location } \\
(n=254)\end{array}$ & & $\begin{array}{l}\text { Radiation of } \\
\text { pain }(n=254)\end{array}$ & \\
\hline Central & 134 (52.8) & yes & 79 (31.1) \\
\hline Left lateral & $91(35.8)$ & no & 175 (68.9) \\
\hline Right lateral & $29(11.4)$ & $\begin{array}{l}\text { Diurnal varia- } \\
\text { tion }(n=254)\end{array}$ & \\
\hline $\begin{array}{l}\text { Type of pain } \\
(n=253)\end{array}$ & & yes & $32(12.6)$ \\
\hline Pricking & 95 (37.5) & no & 222 (87.4) \\
\hline Crushing & $87(34.4)$ & $\begin{array}{l}\text { Severity of } \\
\text { pain - Wong- } \\
\text { Baker FACES } \\
\text { pain rating } \\
\text { scale }(n=254)\end{array}$ & \\
\hline Burning & $45(17.8)$ & $\leq 5$ & $97(38.2)$ \\
\hline Others & $26(10.3)$ & $>5$ & 157 (61.8) \\
\hline
\end{tabular}

\begin{tabular}{|c|c|c|c|}
\hline Factors & $\begin{array}{l}\text { Non-cardiac } \\
\text { cause } \\
n=207\end{array}$ & $\begin{array}{l}\text { Cardiac cause } \\
n=47\end{array}$ & $p$ \\
\hline \multicolumn{3}{|l|}{ Age } & \multirow[t]{3}{*}{$<0.001$} \\
\hline$<40$ & 87 & 3 & \\
\hline$>40$ & 120 & 44 & \\
\hline \multicolumn{3}{|l|}{ Gender } & \multirow[t]{3}{*}{$<0.015$} \\
\hline Male & 48 & 19 & \\
\hline Female & 159 & 28 & \\
\hline
\end{tabular}




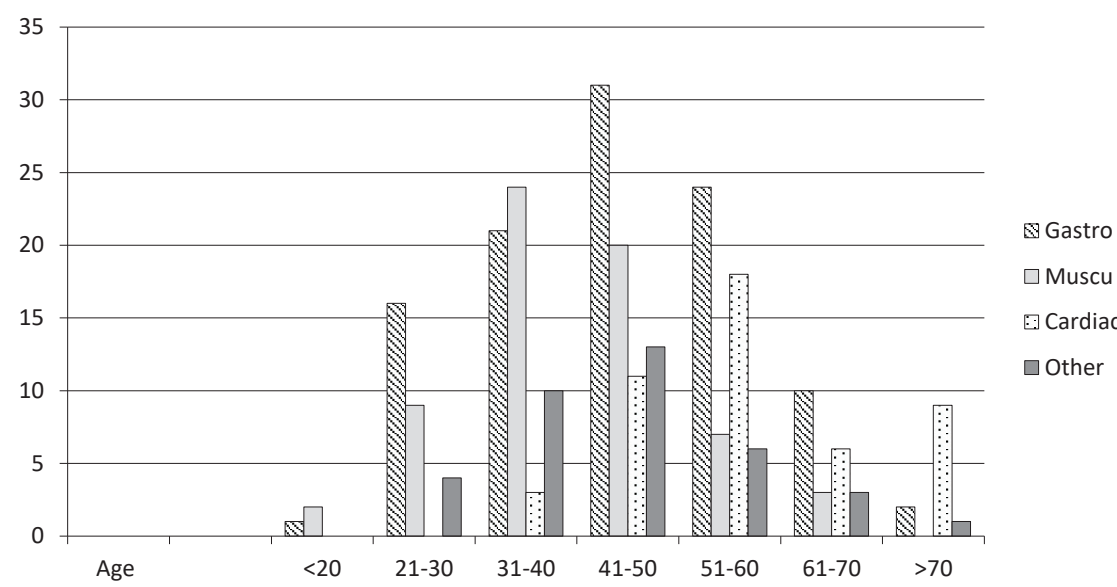

Figure 2. Distribution of the most probable cause of chest pain compared with the age of the patient

\begin{tabular}{|c|c|c|c|}
\hline Factors & $\begin{array}{l}\text { Non-cardiac } \\
\text { cause } \\
n=207\end{array}$ & $\begin{array}{l}\text { Cardiac cause } \\
n=47\end{array}$ & $p$ \\
\hline $\begin{array}{l}\text { Past history } \\
\text { diabetes mel- } \\
\text { litus }\end{array}$ & & & \multirow[t]{3}{*}{$<0.0001$} \\
\hline Present & 41 & 26 & \\
\hline Absent & 166 & 21 & \\
\hline $\begin{array}{l}\text { Past history of } \\
\text { hypertension }\end{array}$ & & & \multirow[t]{3}{*}{$<0.0001$} \\
\hline Present & 53 & 30 & \\
\hline Absent & 154 & 17 & \\
\hline $\begin{array}{l}\text { Past history } \\
\text { of cardiac } \\
\text { disease }\end{array}$ & & & \multirow[t]{3}{*}{$<0.001$} \\
\hline Present & 6 & 8 & \\
\hline Absent & 201 & 39 & \\
\hline $\begin{array}{l}\text { History of } \\
\text { smoking }\end{array}$ & & & \multirow[t]{3}{*}{0.14} \\
\hline Present & 28 & 11 & \\
\hline Absent & 179 & 36 & \\
\hline $\begin{array}{l}\text { History of } \\
\text { alcohol use }\end{array}$ & & & \multirow[t]{3}{*}{0.57} \\
\hline Present & 19 & 4 & \\
\hline Absent & 188 & 43 & \\
\hline
\end{tabular}

\section{Discussion}

\section{Key results}

Our study reports that the most common cause of chest pain in adults presenting to an urban family practice center in South India is gastrointestinal in origin. Most of the patients had central chest pain associated with dyspepsia or nausea. A cardiac cause was diagnosed more in patients with a previous history of diabetes mellitus, hypertension and cardiac disease. To our knowledge, this is the first of such studies done in the Indian population.

\section{Limitations of the study}

Our study had some limitations. The study population was small in comparison to the expected prevalence of chest pain as seen in published literature in other countries. We were not able to follow up on patients diagnosed as having various types of chest pain to see the long-term outcomes. Our ambulatory

care clinic was accessed mainly by females, as working hours were in the morning. As a result, the proportion of females was markedly higher than males.

\section{Interpretation}

Chest pain is the hallmark symptom of acute coronary artery disease to the clinician, as well as to the general public. However, it has been reported that one-third of those who do complain of chest pain do not have acute coronary artery disease [9]. Moreover, the causes of chest pain as diagnosed in primary care differ markedly from emergency or acute care. The prevalence of chest pain of cardiac or non-cardiac etiology has not been studied in India. In India, $70 \%$ of the population visit private practitioners who are general practitioners for common ailments [10]. However, the prevalence of chest pain or the causes of chest pain have not been studied among these visits. In the United States, the cause of chest pain is often non-cardiac in an outpatient visit [11]. Serious cardiovascular conditions account for $50 \%$ of patients presenting with chest pain in the emergency context [12]. Our study had a larger proportion of females due to the outpatient timings which restricted the access to working males; however, in general, females would see their general practitioner more often than males for chest pain [13].

In Switzerland, a study done among all patients presenting in primary care reported that $2.7 \%$ of patients presented with chest pain. Among those who had chest pain, $12 \%$ was of cardiac origin [14]. Our study reports that in $18.5 \%$ of patients, the probable cause of chest pain was of cardiac origin. Non-cardiac chest pain due to gastrointestinal problems, musculoskeletal disorders and psychopathology are found more frequently in general practice [4]. A meta-analysis of the most common causes of chest pain in primary care reported that in $24.5 \%$ to $49.8 \%$ of patient, the cause of chest pain was attributed to chest wall syndrome or musculoskeletal causes, $13.8 \%$ to $16.1 \%$ to cardiovascular causes and $5.6 \%$ to $9.7 \%$ to gastrointestinal disorders [15]. Most of the studies included in this analysis were from developed countries.

In our study, the most common cause of chest pain diagnosed in our practice was gastrointestinal. This is similar to studies in the Asian population, wherein the prevalence of gastroesophageal reflux in patients with non-cardiac chest pain was $66.7 \%$ [16]. Karlaftisa et al. have shown that clinical features such as heartburn, regurgitation, postprandial chest pain and pain relief with anti-reflux drugs are typical of non-cardiac chest pain related NCCP [17]. In an emergency department in South Africa, the most common cause of chest pain was found to be due to respiratory causes, followed by musculoskeletal causes [18]. Diagnosis of the cause of chest pain varies according to the setting, whether ambulatory or emergency, and population. A working knowledge of the common causes of chest pain in 
the target population provides a better "pre-test" probability of one diagnosis from a list of differential diagnoses. This is supplemented by a thorough history and physical examination. It is also useful to define practice populations as rural, remote or isolated to determine referral criteria and standards of care for various symptoms, including chest pain, that present in such practices [19]. Our study helped, in a small context, in demonstrating that the common causes of chest pain in our target ambulatory care patients were related to gastrointestinal causes, characterized by central pain and associated with symptoms of dyspepsia, nausea and vomiting.

\section{Conclusions}

In summary, documenting causes of chest pain in family practice is useful. The most common cause of chest pain was one with non-cardiac, gastrointestinal origin. A cardiac origin of chest pain needs to be suspected when the patient has underlying co-morbidities of diabetes mellitus, hypertension and cardiac disease. There is a need for more studies on the prevalence and causes of all common symptoms that present in general practices across India. This information would be of practical value for the family practitioner, as it would provide pre-test probabilities of common diseases in primary care and guide the diagnostic process. The goal of the family practitioner when evaluating a patient with chest pain is to exclude lifethreatening conditions that would need a referral to tertiary centers. Prior awareness of the most prevalent causes in his/her area of practice would assist towards this goal.

Acknowledgements. We gratefully acknowledge Mr. Murugan Rajaram and Mrs. Grace Rebecca for their valuable support in the analysis phase of this study.

Source of funding: Paper developed using the Fluid research grant financed by Christian Medical College, Vellore, in the year 2015. Conflict of interest: The authors declare no conflict of interests.

\section{References}

1. Cayley NE. Diagnosing the cause of chest pain. Am Fam Physician 2005; 72(10): 2012-2021.

2. Doust J. Diagnosis in a General Practice using probabilistic reasoning. BMJ 2009; 339: b3823, doi: 10.1136/bmj.b3823.

3. Yelland M, Cayley WE, Vach W. Algorithm for the diagnosis and management of chest pain in primary care. Med Clin North Am 2010; 94(2): 349-374.

4. Buntinx F, Knockaert D, Bruyninckx R, et al. Chest pain in general practice or in the hospital emergency department: is it the same? Fam Pract 2001; 18(6): 586-589.

5. Nilsson S, Scheik, M, Engblom D, et al. Chest pain and ischaemic heart disease in primary care. Br J Gen Pract 2003; 53(490): 378-382.

6. Ruigomez A, Rodriguez LAG, Wallander M-A, et al. Chest pain in general practice: incidence, comorbidity and mortality. Fam Pract 2006; 23(2): 167-174

7. Verdon F, Burnand B, Herzig L, et al. Chest wall syndrome among primary care patients: a cohort study. BMC Family Practice 2007; 8(51), doi: https://doi.org/10.1186/1471-2296-8-51.

8. Wong-Baker FACES ${ }^{\circ}$ Pain Rating Scale. Wong-Baker FACES Foundation [Internet]. Wong-Baker FACES Foundation. 2016 [cited 31.10.2016]. Available from URL: http://wongbakerfaces.org.

9. Chierchia SL, Fragasso G. Angina with normal coronary arteries: diagnosis, pathophysiology and treatment. Eur Heart J 1996; 17(Suppl. G): 14-19.

10. Salvi S, Apte K, Madas S, et al. Symptoms and medical conditions in 204912 patients visiting primary health-care practitioners in India: a 1-day point prevalence study (the POSEIDON study). Lancet Global Health 2015; 3(12): e776-e784.

11. Klinkman MS, Stevens D, Gorenflo DW. Episodes of care for chest pain: a preliminary report from MIRNET. Michigan Research Network. $J$ Fam Pract 1994; 38(4): 345-352.

12. Knockaert DC, Buntinx F, Stoens N, et al. Chest pain in the emergency department: the broad spectrum of causes. Eur J Emerg Med 2002; 9(1): 25-30.

13. Bosner T, Becker A, Haasenritter J, et al. Chest pain in primary care: epidemiology and pre-workup probabilities. Eur J Gen Pract 2009; 15(3): 141-146.

14. Verdon F, Herzig L, Burnand B et al. Chest pain in daily practice: occurrence, causes and management. Swiss Med Wkly 2008; 138(23-24): 340-347. doi: 2008/23/smw-12123.

15. Haasenritter J, Stanze D, Widera G, et al. Does the patient with chest pain have a coronary heart disease? Diagnostic value of single symptoms and signs - a meta-analysis. Croat Med J 2012; 53(5): 432-441, doi: 10.3325/cmj.2012.53.432.

16. Mohd H, Qua CS, Wong CH, et al. Non-cardiac chest pain: prevalence of reflux disease and response to acid suppression in an Asian population. J Gastroenterol Hepatol 2009; 24(2): 288-293, doi: 10.1111/j.1440-1746.2008.05702.x.

17. Karlaftisa A, Karamanolisa G, Triantafyllou K, et al. Clinical characteristics in patients with non-cardiac chest pain could favor gastroesophageal reflux disease diagnosis. Ann Gastroenterol 2013; 26(4): 314-318.

18. Geyser M, Smith S. Chest pain prevalence, causes, and disposition in the emergency department of a regional hospital in Pretoria. Afr J Prim Health Care Fam Med 2016; 8(1): 1048, doi: 10.4102/phcfm.v8i1.1048.

19. Petrovcic R. Defining rural, remote and isolated practices: the example of Slovenia. Fam Med Prim Care Rev 2016; 18(3): 391-393.

Tables: 3

Figures: 2

References: 19

Received: 04.12.2016

Revised: 05.03.2017

Accepted: 18.05 .2017
Address for correspondence:

Prof. Prince Christopher Rajkumar Honest

Department of Family Medicine

Christian Medical College

Schell Eye Campus, Arni Road, Vellore

India

Tel.: +914163071231

E-mail: prince.christopher@gmail.com 